\title{
Erratum to: Mass spectrometric analysis of products of metabolic glycan engineering with azido-modification of sialic acids
}

\author{
Edward Bodnar $^{1}$ - Céline Raymond ${ }^{2,3}$ - Paul G. Lopez ${ }^{1}$ - Carina Villacrés ${ }^{4}$. \\ Michael Butler $^{4}$ • Ian C. Schoenhofen ${ }^{5}$ - Yves Durocher ${ }^{2,3}$ • Hélène Perreault ${ }^{1}$
}

Received: 27 October 2015 / Accepted: 27 October 2015 / Published online: 9 November 2015

(C) Springer-Verlag Berlin Heidelberg 2015

\section{Erratum to: Anal Bioanal Chem}

\section{DOI 10.1007/s00216-015-9010-x}

The original version of this article unfortunately contained a mistake. The presentation of Figs. 1, 3 and 4 was incorrect. The final version of these figures is given below and the original article was corrected.

The online version of the original article can be found at http://dx.doi.org/ 10.1007/s00216-015-9010-x.

Hélène Perreault

Helene.Perreault@umanitoba.ca

1 Chemistry Department, University ofManitoba, Winnipeg, MB R3T 2N2, Canada

2 Human Health Therapeutics Portfolio, National Research Council Canada, Montreal, QC H4P 2R2, Canada

3 Département de biochimie et médecine moléculaire, Université de Montréal, Montreal, QC H3C 3J7, Canada

4 Microbiology Department, University of Manitoba, Winnipeg, MB R3T 2N2, Canada

5 Human Health Therapeutics Portfolio, National Research Council Canada, Ottawa, ON K1A 0R6, Canada 
a

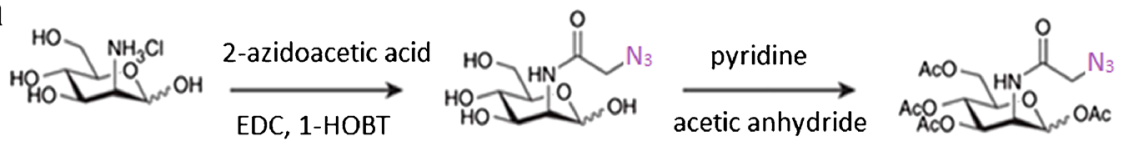

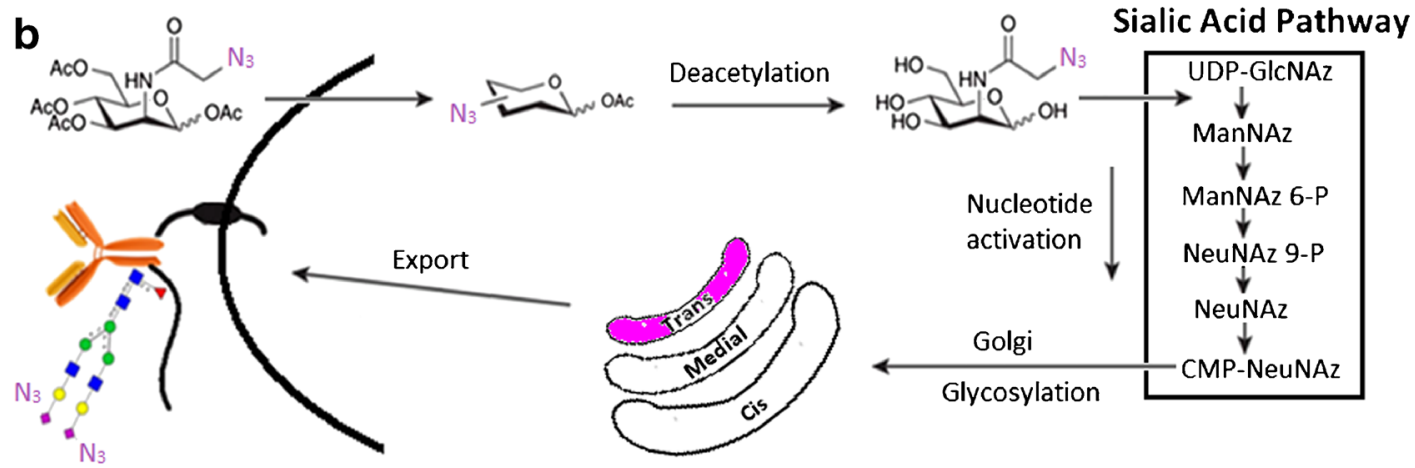

C
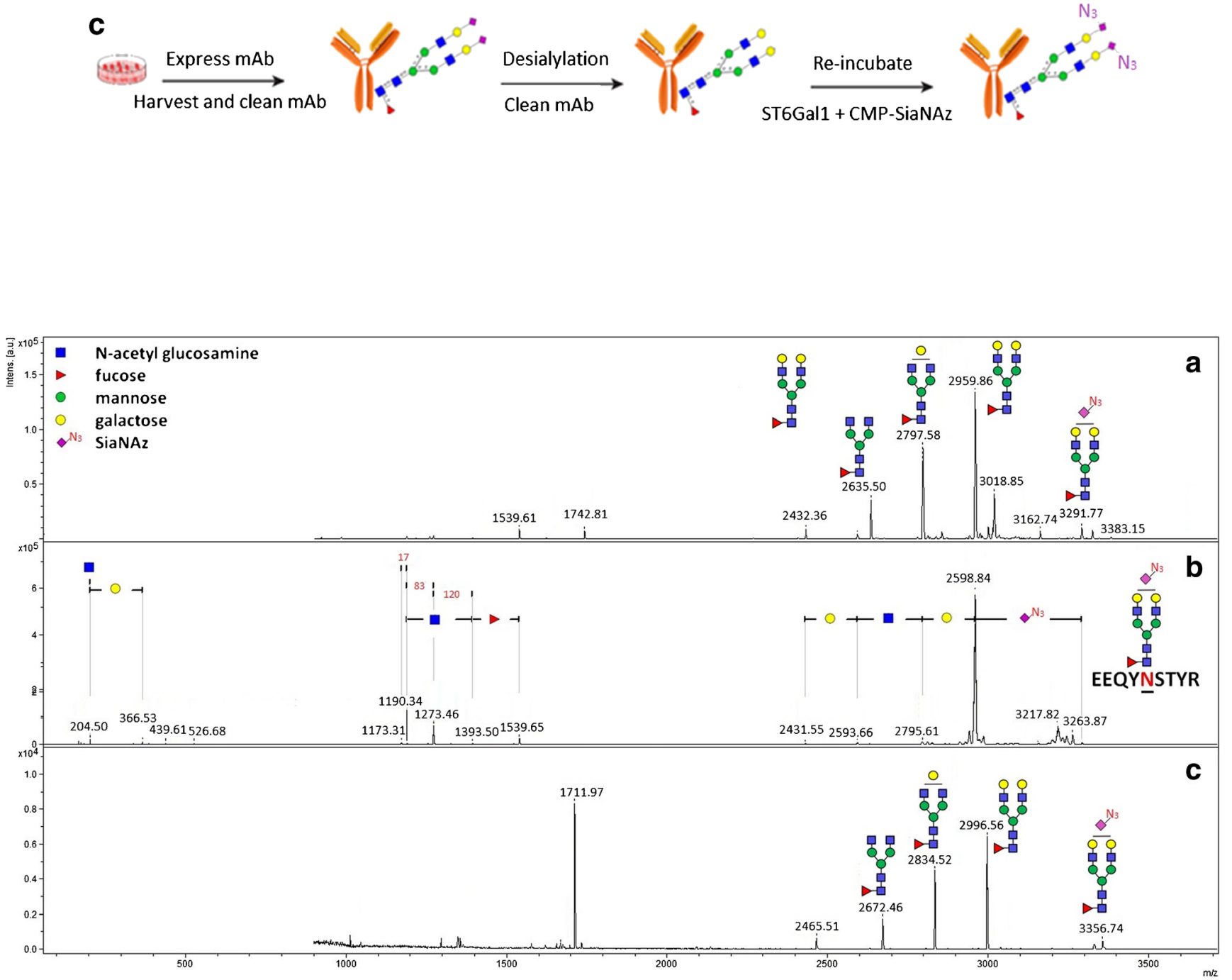


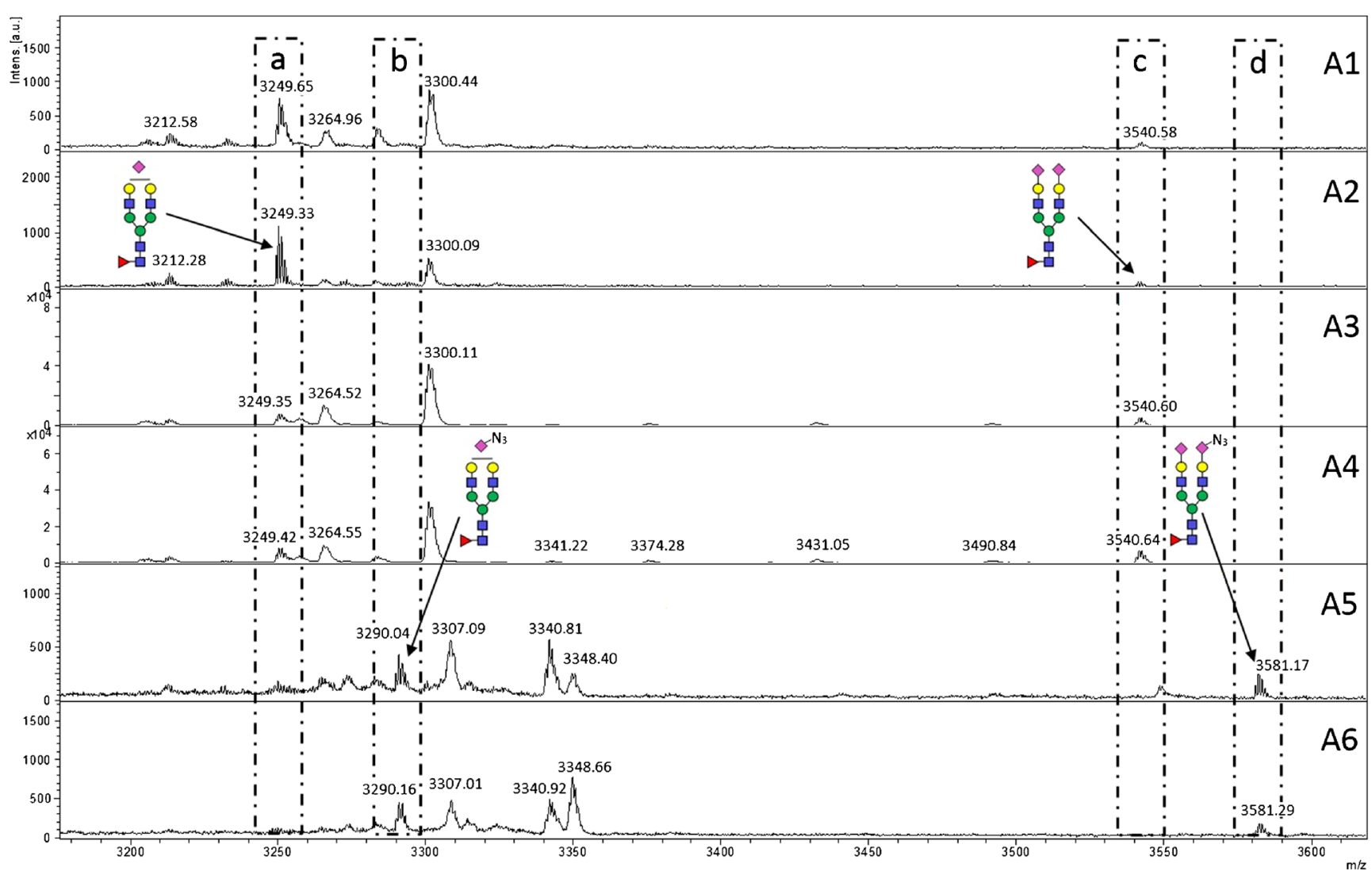

